\title{
Production of Bio-Oil from Municipal Solid Waste by Pyrolysis
}

\author{
Muhammad Saiful Islam, ${ }^{\mathrm{a}}$ M. Yunus Miah, ${ }^{\mathrm{b} *}$ Mohammad Ismail, ${ }^{\mathrm{a}}$ Mohammad Shah Jamal, \\ Sujit Kumar Banik ${ }^{b}$ and Manoranjan Saha ${ }^{a}$
}

\author{
${ }^{a}$ Department of Applied Chemistry \& Chemical Engineering, University of Dhaka, Dhaka-1000, Bangladesh. \\ and ${ }^{b}$ Institute of Fuel Research and Development , BCSIR, Dhaka-1205, Bangladesh.
}

\begin{abstract}
.Abstract
Municipal solid waste was pyrolyzed in a tubular reactor under vacuum. The effect of pyrolysis temperature and holding time on the product yields were investigated and the optimum conditions for pyrolysis were settled. The products of the pyrolysis were liquid pyrolytic oil, solid char and gaseous mixture. The pyro-oil was collected in a series of ice-cooled collectors. The uncondensed gas was blown off and the solid char was collected from the pyrolyser as a residue. The pyro-oil was then analyzed for fuel properties and chemical composition. The experimental result of gas chromatography \& mass spectroscopy showed that the pyro-oil derived from the pyrolysis of municipal solid waste contained considerable amounts of carbonyl groups and/or oxygen content, resulting in low $\mathrm{pH}$ and low heating value.
\end{abstract}

Key words: Municipal solid waste, Pyrolysis, Yield, Pyrolytic oil, Fuel properties, Chemical composition

\section{Introduction}

The conventional sources of energy have been depleting at an alarming rate and hence the focus on alternative renewable source of energy is increasing. As a result, biomass as a renewable energy source has continued to attract increased attention (Bridgwater and Bridge, 1991). A lot of research in this area is in progress using different solid biomass as the feed material (Besler et al., 1992). Pyrolysis, an important thermo-chemical route is becoming an increasingly popular option. Thus, there is a great potential in developing technology to convert biomass into fuels and chemicals, reducing waste management cost (Raveendran et al., 1996). Needless to say, municipal solid waste (MSW) is a common biomass obtained from any city area of all over the world as well as in Bangladesh. It is a common waste management problem. The demand of fuel and various chemicals are also increasing day by day. Every year the country is expending a lot of foreign exchange for importing petroleum and related products. Thus, the pyrolysis method may be considered as a promising option for the treatment of MSW and as a good technology for resource recovery. Due to the lower contents of sulfur and nitrogen utilization of the derived energy does not add sulfur dioxide, nitrogen oxides and no net carbon dioxide, which are greenhouse gases to the atmospheric environment, in contrast to fossil fuels (Ani and Islam, 1997). Considering the above advantageous environmental aspects, disposal and overall management system of MSW,

\footnotetext{
* Corresponding author: E-mail: pdyunus@yahoo.com
}

this study was undertaken to produce the bio-oil from MSW. On an average 3,000 to 4,000 tons of MSW are obtained daily from Dhaka metropolitan area according to the report of Dhaka City Corporation (http://www.dhakacity.org /Page/Hotlinks_menu/Home/Category/hotlink/Link/0/Id/12/ Info). The MSW are mostly mixtures of organic food wastes, papers, broken glasses, metals, plastics, etc. The organic food wastes, that are the cellulosic biomass, were the target raw materials in this experiment. All of the products of pyrolysis have found their significant applications. The uses of the overall products are as follows:

* Bio-oil/pyrolysis oil can be used in boilers, furnaces, ship engines, train engines and turbines (Hogan, 1996).

* After minor upgradation of bio-oil (Brown and Holmgren, 2001), several organic chemicals are found which can be used in chemical industry, laboratory and in pharmaceutical industry, etc.

* Char can be used for activated carbon production, reinforcing fillers in plastic and rubber goods and in ceramic brick industry (Grover et al., 1992).

* Gaseous products can be used in generator to produce electricity.

Thus a problematic waste is converted into a total usable products and can solved the energy crisis of the country and of the world in a significant amount. 


\section{Material and Methods}

\section{Biomass}

Collection, sorting and drying of MSW: MSW was collected from the dustbin of BCSIR residential area of Dhaka city. Then glass cullet and metallic substances were sorted and separated out from MSW. The raw materials were then solar dried. The main characteristics of MSW are given below.

\section{Table I. Characteristics of raw MSW}

\begin{tabular}{l|c|c}
\hline Characteristics & $\begin{array}{c}\text { Raw MSW } \\
\text { as Collected }\end{array}$ & $\begin{array}{c}\text { MSW after } \\
\text { solar drying }\end{array}$ \\
\hline Moisture, \% wt. & $50-70$ & 14.36 \\
Ash , \% wt. & $10-15$ & 8.17 \\
Combustible matter, \% wt. & $60-70$ & 76.55 \\
Average bulk density, kg/m³ & $350-450$ & 230 \\
\hline
\end{tabular}

\section{Pyrolysis system}

The solar dried solid waste was then introduced into a horizontal tube furnace. Inside the furnace, there was a stainless steel made pyrolyser in which the wastes were placed. A vacuum pump was set to obtain high vacuum inside the pyrolyser, which was between 0.003 to $0.001 \mathrm{mmHg}$ pressure. The temperature of pyrolyser was $400-550^{\circ} \mathrm{C}$. The fluid (mixture of liquid and gas) was allowed to come out through the vacuum line of the pyrolyser and the solid char was collected from the stainless steel mesh as residue. The fluid

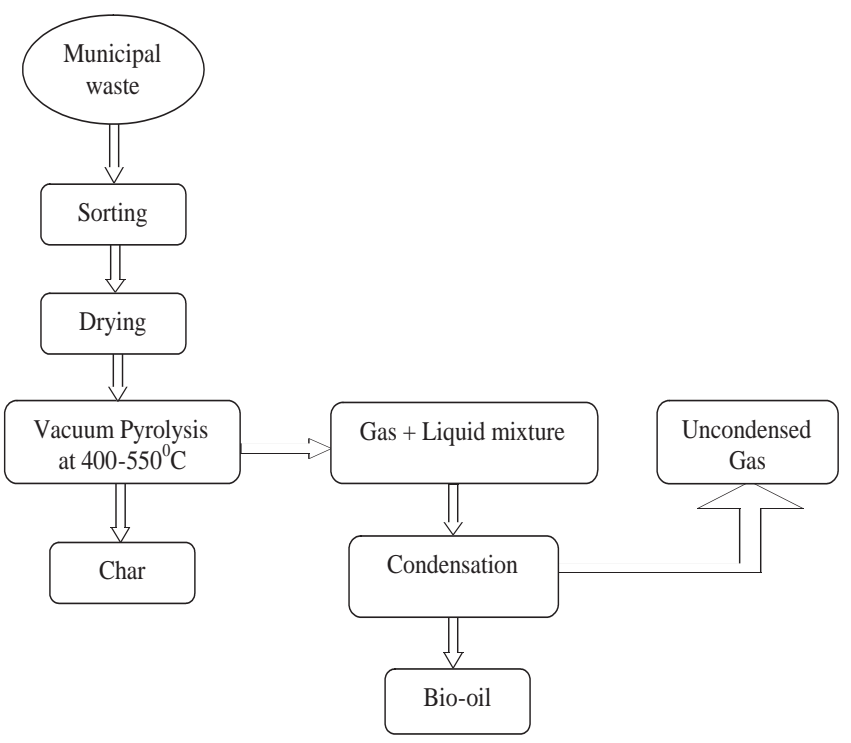

Fig 1. Flow sheet for the production of Bio-oil from MSW from the pyrolyser was condensed in condenser and bio-oil was obtained. Uncondensed gas was blown off. Total procedure of production is shown in Fig. 1.

\section{Results and Discussion}

\section{Product yields}

The products obtained from the pyrolysis process were liquid oil, solid char and gas. The liquid was found to be a single phase dark brown colour. From the several experiments, it was observed that the yields of liquid product and solid char vary with process conditions. The maximum liquid yield was obtained at a temperature of $500^{\circ} \mathrm{C}$ and $35 \mathrm{~min}$ utes duration under $0.001 \mathrm{mmHg}$ pressure. The maximum yield was 45 wt\% of dry MSW feed. At temperature lower than $500^{\circ} \mathrm{C}$ the liquid yield was lower and char yield was higher. On the other hand, at temperature higher than $500^{\circ} \mathrm{C}$ the char was found to be less with a reduction in liquid yield; however the gas yield was observed to be higher. The reason for lower liquid yield at lower temperature may be due to the fact that the temperature rise was not enough for complete pyrolysis to take place yielding less liquid and more solid char. On the other hand at higher temperature there is a possibility of secondary decomposition reaction to lighter gaseous products rendering lower liquid and char yields. The variation in liquid yields with reactor temperature is presented in Fig. 2.

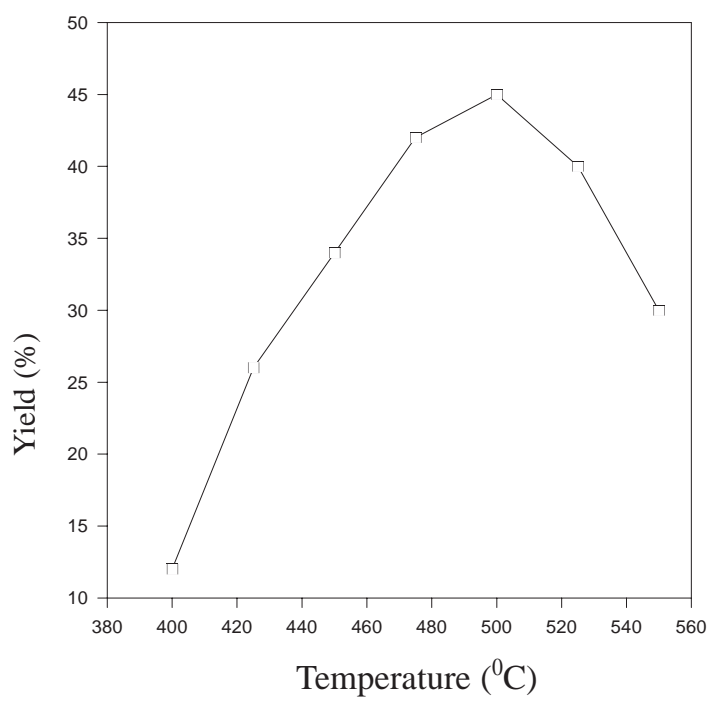

Fig. 2. Effect of pyrolysis temperature on liquid product yields

It was observed that the product obtained increased with time, but after 35 minutes the liquid yields did not significantly increase. The effect of time on the liquid yields at $500^{\circ} \mathrm{C}$ is presented in Fig.3. 


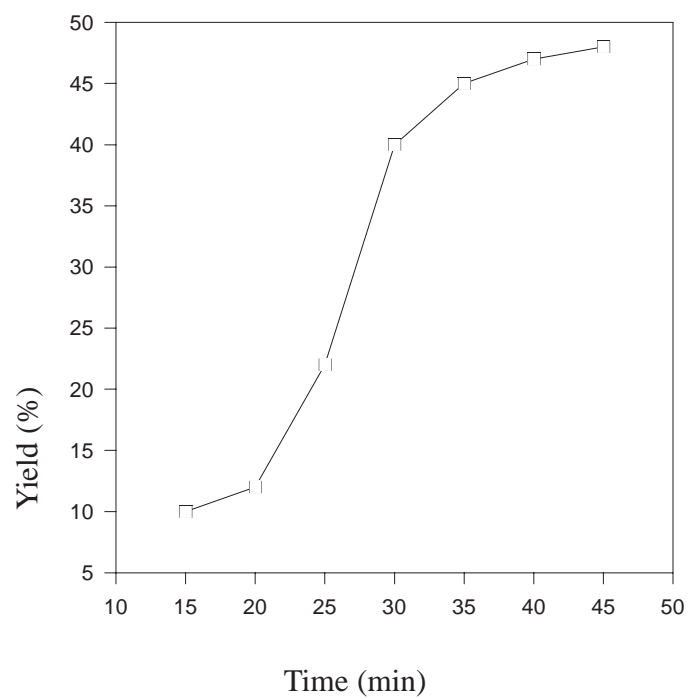

Fig. 3. Effect of pyrolysis time on liquid products yields

\section{Oil product analysis}

\section{Physical and chemical characteristics}

Biomass pyrolysis oils are not standardized products. They can exhibit in a wide range of properties and composition, according to the feedstock and pyrolysis technique employed. Product characteristics may also vary with the process conditions. The composition of the raw material MSW may vary from place to place and even from time to time at the same place. However the common features of

Table II. Physical / Fuel properties of MSW pyro-oil

\begin{tabular}{l|c|c}
\hline Properties & $\begin{array}{c}\text { MSW } \\
\text { pyro-oil }\end{array}$ & $\begin{array}{c}\text { Typical } \\
\text { pyro-oil }\end{array}$ \\
\hline Density, g/cc & 1.02 & 1.12 \\
Kinemetic viscosity & & \\
@ $40^{0} \mathrm{C}, \mathrm{cSt}$ & 7.05 & $5-20$ \\
$\mathrm{pH}$ value & 3.27 & 2.5 \\
Water content, \% wt. & 28 & 20 \\
Heating value, MJ/kg. & 12.01 & 18 \\
Flash point, ${ }^{0} \mathrm{C}$ & 75 & 85 \\
Pour point, ${ }^{0} \mathrm{C}$ & -7 & -15 \\
Ash content, \% wt. & 0.04 & 0.10 \\
Sulfur content, \% wt. & not detectable & trace \\
Nitrogen content, \% wt. & not detectable & trace \\
Acid value, mg KOH/g oil & 4.69 & $2-7$ \\
Carbon residue, \% wt. & 0.34 & 0.40 \\
\hline
\end{tabular}

pyrolysis liquid products are usually highly acidic with high water content, moderate heating value and very low sulfur content (Table II). The results agree with an earlier study (Rick and Vix, 1991). The most prominent is the acidic nature of the oil due to high oxygen content. The pyro-oil obtained had a $\mathrm{pH}$ lower than 4, indicating it`s corrosive nature. The high water content of pyro-oil is due to formation of water in pyrolysis process. The lower heating value of the oil is due to the high water content and presence of carbonyl compounds. The ash content in the oil is very negligible.

\section{Compositional analysis}

Gas chromatography-mass spectroscopy (GC-MS) results of the derived pyro-oil indicated the compositions of the liquid products, presented in Table III followed by GC peak (Fig. 4) according to their carbon numbers. The oil was found to be in between $\mathrm{C}_{5}$ to $\mathrm{C}_{16}$ aliphatic and aromatic compounds

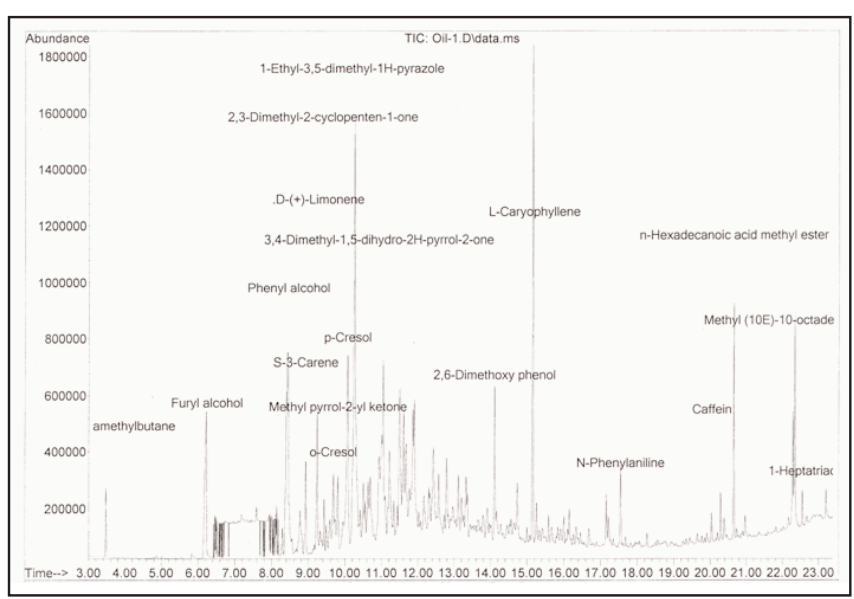

Fig. 4. GC-peak of MSW pyro-oil

The pronounced oxygenated functional groups of $-\mathrm{OH}$; $>\mathrm{CO}$, $-\mathrm{COOH}$ and aromatic compounds showed that the oil were highly oxygenated and therefore, very acidic as has also been indicated by the low $\mathrm{pH}$ value. The high fraction of oxygenated compounds reduces the calorific value of the oil since $\mathrm{C}=\mathrm{O}$ bonds do not release energy during combustion. The presence of $\mathrm{C}-\mathrm{H} ; \mathrm{C}=\mathrm{C}$; and alcohols indicate that the liquids have a potential to be used as fuel. The various highly valued compounds that were indicated by GC-MS analysis can be separated by fractional distillation. These can be used in chemical industries, textiles, pharmaceuticals, etc. 
Table III. The chemical compounds in MSW pyro-oil

\begin{tabular}{l|l|l}
\hline Chemical compounds & \multicolumn{1}{|c|}{$\begin{array}{c}\text { Molecular } \\
\text { formula }\end{array}$} & \multicolumn{1}{|c}{$\begin{array}{c}\text { Boiling } \\
\text { point in }{ }^{0} \mathrm{C}\end{array}$} \\
\hline $\begin{array}{l}\text { Furyl alcohol } \\
\text { Methyl pyrol-2-yl ketone } \\
\text { o-Cresol }\end{array}$ & $\begin{array}{l}\mathrm{C}_{5} \mathrm{H}_{6} \mathrm{O}_{2} \\
\mathrm{C}_{6} \mathrm{H}_{7} \mathrm{NO}\end{array}$ & 171.1 \\
$\left(\mathrm{CH}_{3}\right) \mathrm{C}_{6} \mathrm{H}_{4}(\mathrm{OH})$ & $200-202$ \\
p-Cresol & $\left(\mathrm{CH}_{3}\right) \mathrm{C}_{6} \mathrm{H}_{4}(\mathrm{OH})$ & 191.5 \\
2,3-Dimethyl-2- & & \\
cyclopenten-1-one & $\mathrm{C}_{7} \mathrm{H}_{10} \mathrm{O}$ & 165 \\
2,2.3.3-Tetramethylbutane & $\mathrm{CH}_{3} \mathrm{C}\left(\mathrm{CH}_{3}\right)_{2} \mathrm{C}$ & 128 \\
& $\left(\mathrm{CH}_{3}\right)_{2} \mathrm{CH}_{3}$ & \\
$\begin{array}{l}\text { Phenyl alcohol } \\
\text { 2,6-Dimethoxy phenol } \\
\text { Caffeine }\end{array}$ & $\mathrm{C}_{8} \mathrm{H}_{10} \mathrm{O}$ & 201.8 \\
N-Phenyl aniline & $\mathrm{C}_{8} \mathrm{H}_{10} \mathrm{O}_{3}$ & 261 \\
L-Caryophylene & $\mathrm{C}_{8} \mathrm{H}_{10} \mathrm{~N}_{4} \mathrm{O}_{2}$ & 175 \\
n-Hexadecanoic acid & $\left(\mathrm{C}_{6} \mathrm{H}_{5}\right)_{2} \mathrm{NH}$ & 302 \\
\hline
\end{tabular}

\section{Conclusion}

The pyrolysis oils were single-phase liquid products of brownish dark color with acrid smell. The hazardous product creating agents sulfur and nitrogen were not detected in the oils. GC-MS analysis showed that the liquids were dominant with oxygenated species. Hence, it is important to deoxygenate the liquids by some upgrading technology. The physical properties analysis showed that the oils were acidic in nature with lower viscosity. The oils possessed favorable pour and flash points. The heating values of the oils were moderate. However, the values are similar to other biomass derived pyrolysis oils. From this study it is found that the pyrolysis of MSW may be a future potential alternative source of liquid hydrocarbon fuels and chemical compounds feed stock. Further characterization studies on pyrolysis liquid products from the solid wastes should be conducted to provide ways of utilizing the liquid as fuels in boiler, internal combustion engines, etc., or as value added chemicals. Catalytic upgrading of the liquid product to higher utility fuels, using various types of catalyst may also be studied.

\section{References}

Ani F. N. and Islam M. N. (1997) Liquid oil from fluidized bed pyrolysis of rice husk. In: Proceeding of Second Jordanian International Conference of Mechanical Engineering, JIMEC 97. Amman, Jordan, June 2-5, pp. 270-276.
Besler S., Horne P. A. and Williams P. T. (1992) The fuel properties of biomass derived pyrolytic oils and catalytically upgraded products. In: proceedings of the Second World Renewable Energy Congress. September 13-18, United Kingdom (CD version).

Bridgwater A. V. and Bridge, S. A.(1991) A review of biomass pyrolysis and pyrolysis technologies. Elsevier Applied Science Journal., 105 (8): 11-92.

Brown R. C. and Holmgren J. (2001) Fast pyrolysis and biooil upgrading. Biomass and Bioenergy Journal. 27(3) : 45-52.

Demirbas A. (2001) Biomass resource facilities and biomass conversion processing for fuels and chemicals. Energy Conversion and Management Journal. 42(11): 13571378.

Grover P. D., Rao T. R., Iyer P. V. R. and Sambi S. S. (1992) Recovery of value added products and energy from biomass. In: proceedings of the World Conference on Agrarian Reform and Rural Development, Kuala Lumpur, Malaysian, pp:164-170

Hogan E. (1996) Bioenergy development program-thermochemical conversion. In bio-oil production and utilisation. (CPL Press, Berkshire, United Kingdom) pp.1-4.

McKendry P. (2002) Energy production from biomass (part 2) : conversion technologies. Bioresource Technology Journal. 83(1) : 47-54

Mohan D., Charles U., Pittman J. and Philip H. (2006) Pyrolysis of Wood/Biomass for Bio-oil: A Critical Review. Energy and Fuels Journal., 20(3) : 848-889

Raveendran K. Ganesh A. and Khilar K. C. (1996) Pyrolysis characteristics of biomass and biomass components. Elsevier Applied Science J., 75(8): 987-998

Rick F. and Vix U. (1991) Product standards for pyrolysis products for use as fuel in industrial firing plants. Elsevier Applied Science Journal., 38(3):177-218.

Yaman S. (2004) Pyrolysis of biomass to produce fuels and chemical feedstocks. Elsevier Applied Science Journal., 45(5) : 651-671

Received : May 19, 2009;

Accepted : September 09, 2009 